\title{
Investigación/Arte/Vida: entre intersticios, procesiones y progresiones
}

\author{
Laura DE MiguEL ÁlvAREZ ${ }^{1}$ \\ lmiguela@nebrija.es
}

Enviado: $15 / 05 / 12$

Aceptado: $22 / 11 / 12$

\section{RESUMEN}

Con este artículo, se pretende ofrecer métodos y planteamientos desde los que poder iniciar nuestro proyecto de investigación en el área de las Bellas Artes, desde una perspectiva en la que la experiencia de vida es tomada en cuenta dentro del propio proceso indagador. Así como el cuerpo y mente de la figura del investigador, que se visibiliza a la vez que posibilita crear nuevas formas de representar dicho proceso apoyadas en las ya existentes, regenerándolas, o concibiendo otras nuevas.

Palabras clave: Investigación, arte, vida, experiencia, narración, tesis doctoral, creación.

\section{Referencia normalizada}

De Miguel Álvarez, L. (2012). "Investigación/Arte/Vida: entre intersticios, procesiones y progresiones". En Arteterapia: Papeles de arteterapia y educación artística para la inclusión social Vol.7: páginas 27-40. Madrid. Servicio de publicaciones UCM.

\section{SUMARIO}

Quien soy. Investigación/Arte/Vida. Poso.

\section{Research/ART/Live: Between interstices, processions and progressions}

\begin{abstract}
With this article, one tries to offer methods and expositions from which to be able to initiate our project of research in the area of the Fine arts, from a perspective in that the experience of life examiner is taken in account inside the own process. As well as the body and mind of the figure of the investigator, which it is made see simultaneously that it makes possible to create new ways of representing the above mentioned process supported on the already existing ones, regenerating, or creating new others.
\end{abstract}

Keywords: Research, art, life, experience, story, doctoral thesis, creation.

\section{CONTENTS}

Who I am. Research/arts/life. Sediment.

${ }^{1}$ Licenciada (2004) y Doctora (2010) en Bellas Artes por la UCM. Actualmente, creadora multidisciplinar, profesora en la Universidad Antonio de Nebrija en las carreras de Bellas Artes e Ingeniería Industrial. También es parte del equipo de formadores de la Concejalía de Cultura del Ayto. de Alcorcón, en el área de artes plásticas. Colabora con diversas entidades sin ánimo de lucro, al igual que con diferentes proyectos de investigación, en la búsqueda de nuevas formas de narrar la experiencia para hacerla significante y parte indivisible de la práctica e investigación artística. 


\section{QUIEN SOY}

Supongo que lo más apropiado cuando comienzas una comunicación con alguien, es presentarse. De algún modo, ya que este acto convencional y protocolario no es posible realizarlo por ambas partes, voy a tratar de dar una pincelada de mi persona, de la parte de mi existencia que me ha llevado al mundo de la investigación. Metidos en el marco que nos ocupa, la mejor manera de dar cuenta de ellos es denominar el contenido que voy a narrar a continuación como: Estado de mi cuestión ${ }^{2}$. Estado de mi cuestión.

- Antecedentes: Desde niña siempre tuve claro que quería ser pintora. Muchos esperaban que mi interés por el arte se desarrollara como el de mis antecesores, larga estirpe de peluqueros, de los de antes, de los artistas-peluqueros...; la verdad es que ésta era una profesión que me gustaba, pero no, yo quería ser pintora. Aún siendo buena estudiante, no me importaba dejar de estudiar y formarme en escuelas y/o academias de educación no reglada para conseguir mi propósito, ya que siendo tan pequeña, desconocía que existiese una carrera en la que, a través de estudios reglados universitarios, pudiera formarme para conseguir mi meta.

Finalicé mis estudios de la Licenciatura en el año 2004.

Seguidamente, y compaginándolo con algunos trabajos precarios como profesora de pintura y danza (pues otras de las formaciones que recibí desde niña, hasta los 20 años, fueron estudios de Danza Clásica por el Real Conservatorio de Danza de Madrid), acabé dirigiendo campamentos de verano ${ }^{3}$, experiencia que, unida a algunas anteriores dentro del marco social (en centros de día, centros de menores de régimen cerrado, centros ocupacionales...), supondrán la flecha que comienza a trazar mi camino. Un camino, como el que atraviesa los campos sembrados, dibujado por las ruedas de un carro (coche) por el paso continuado, uno detrás de otro. Sendero de dos líneas paralelas, que simbólicamente podrían corresponderse con el papel que ha ido desempeñando en mi día a día el arte y la interrelación social. Siguiendo con la metáfora visual que podemos imaginar, el espacio que queda entre ambos, esa hierba alta inclinada hacia la dirección que más se transita, podría representar el espacio de reflexión que ha quedado marcado por cada experiencia compartida, cada lugar habitado y cada resultado y/o planteamiento al que se ha llegado, que de algún modo, nos conducen hacia los siguientes, creciendo, transformándose, evolucionando y adaptándose "al carro" que los transita, a la línea sinuosa que dibuja la persona que conduce el automóvil, a su vida. Montados en el carro, con-

\footnotetext{
${ }^{2}$ El apartado de Estado de la cuestión de un proyecto de investigación, suele contener: los antecedentes y el contexto de la problemática de la investigación, el desarrollo y síntesis de los principales aportes realizados hasta el momento y la exposición de los problemas pendientes (Maria Luisa Zubizarreta, 1998: 64). En este texto, Estado de mi Cuestión, plantea: mis antecedentes personales y el contexto de los mismos, síntesis de las principales aportaciones que se han realizado hasta el momento a partir de la mi práctica investigadora y la exposición de las vías abiertas que se han dejado con dichas a aportaciones.

${ }^{3}$ Programa Aulas de la Naturaleza. MEC (BOE n 27, 2007: 4559).
} 
duciéndolo a través del sendero de la investigación durante los estudios de doctorado, concretamente con la confección del Diploma de Estudios Avanzados, llegamos a la problemática.

- Contexto, problemática y desarrollo: En este caso, me ceñí a lo establecido, a los manuales sobre investigación que describen estructuras establecidas de cómo presentar dicho trabajo. Al finalizarlo, me quedó un sabor agridulce ya que, aunque había logrado una buena nota con él, éste no acababa de encajar con lo que yo entendía entonces por una investigación en el marco del arte aplicado a la integración social, aunque en contenido pudiera parecer que sí, no lo hacía en forma narrativa, estructura...

Comienzo entonces LA TESIS.

Cuatro años sucederán a este comienzo, tiempo que puedo resumir con la siguiente secuencia de palabras:

Rumbo a ciegas: Inercia, Incertidumbre y Restos - Hallazgo de un nuevo ser, encuentro con la plenitud.

Sucesión que comprenderán dos de los epígrafes principales que se pueden encontrar en el guión del trabajo gracias al que me doctoré, titulado: La huella, la tela, el blanco y el negro en la manifestación de ser. Modelo de confección autoidentitaria del artista-investigador-educador. (De Miguel Álvarez, Laura. 2010).

- Algo que ofrecer: Gracias a la experiencia de parir ${ }^{4}$ mi tesis doctoral, encontré un modelo que ofrecer a la comunidad investigadora en el campo de las Bellas Artes con la que comparto los mismos intereses de investigación, pero siempre desde una perspectiva que tras haber acabado dicho trabajo, y haber acudido a diferentes congresos y seminarios sobre Investigación Artística, me ha permitido vislumbrar que se encuentra dentro de un paradigma en Investigación Artística emergente que relaciona directamente la experiencia artística con la experiencia de vida, para conseguir la construcción de un sentido (conocimiento) a través del círculo reflexivo generado. De este modo, llegamos a la confección de una estructura de trabajo de tesis singular, ya que en ella no solo se ofrecen nuevas formas de narrar la experiencia, sino que también se observa en cada imagen y en la relación que éstas establecen con los textos que las enmarcan, que en el proceso de confección autoidentitaria narrado la experiencia de vida y la experiencia de tesis van fusionadas.

\footnotetext{
${ }^{4}$ El verbo parir se utiliza dentro de mi proceso de transformación identitaria durante la investigación, como analogía que presenta el diseño, proceso de confección de tesis y posterior defensa, con el estado gestacional de la mujer. Ya que, en la propia tesis, establezco un paralelismo visible en imágenes y sentido en texto, en algunos de los apartados tratados, como por ejemplo: $\mathrm{Si}$, es corta, pero intensamente vivida, haciendo de ella tu propia obra de arte, ensalza al máximo su belleza en los momentos carnalmente más dolorosos, como por ejemplo el nacimiento (parto) de mi hija. (de Miguel Álvarez, Laura. 2010. Pág. 350.)
} 


\section{INVESTIGACIÓN/ARTE/VIDA}

En la línea sinuosa descrita anteriormente, existe un espacio entre arte e interrelación social que comprende el concepto que contiene y une a ambos, la experiencia de vida. Perspectiva de investigación desde la que se ofrece un nueva forma estructural de tesis que nos ayuda a establecer de forma simultánea diferentes modos por las que nos aborda el conocimiento, el proceso de evolución y transformación de nuestro ser, a través del camino que hemos venido a recorrer; camino que queda recogido (congelado) en una investigación doctoral para la Facultad de Bellas Artes de la Universidad Complutense de Madrid. La tesis doctoral presentada en este texto, de algún modo, se yergue como ejemplo de que el ARTE $^{5}$ puede jugar un papel indispensable en dicho proceso transformador ya que gracias a permitir mostrar la experiencia procesual del sujeto investigador en relación con el Otro, sitúa al ARTE en un contexto de permite dar cuenta del de nuestras decisiones dez, 2011). A la vez que plantea un tipo de performativa que sitúa al dentro de la experiencia, que se confecciona como proceso reformador.

La confección del texto transformadora.

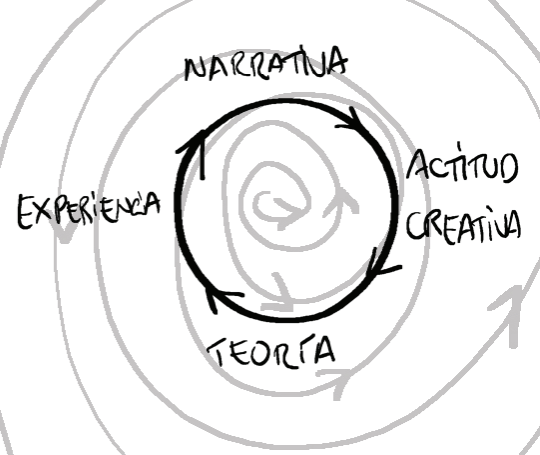
relaciones que nos dónde y el porqué (Fernando Hernánnos aproxima y investigación cuerpo en un lugar a través del relato parte del propio En el momento de finalizar el discurso de la investigación, me di cuenta que el propio texto, durante su creación, había contribuido a redefinir la mirada que tenía del mundo, de la vida, convirtiéndose en una mirada transformadora hacia una nueva forma de ser y existir en él. Al respecto de este planteamiento de escritura transformadora, Vanessa Aguilar nos explica en su novela El abrazo del Oso (2011: 89):

Cuando concluí la novela mi visión de la vida se había transformado. Todos y cada uno de los relatos personales que se hallaban inmersos en ella habían tenido como propósito abrir mis ojos a una nueva realidad existencial.

Tesis doctoral $=$ creación libre.

Al igual que hay manuales de cómo hacer una tesis en Ciencias Sociales, he llegado a la conclusión en este tiempo de que no es posible establecer un libro de "¿Cómo hacer una tesis en Investigación Artística?" por la singularidad de que lo que implica esta perspectiva es el concepto que poseen las artes en sí de la creación/interpretación libre. Concepto del que nos habla Elliot Eisner (2004:239-
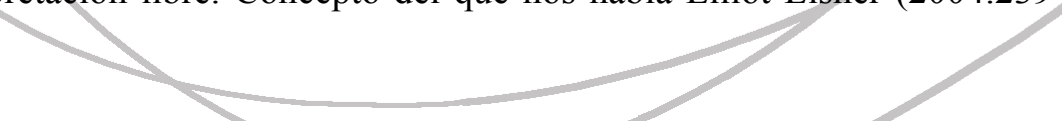

${ }^{5}$ ARTE (en mayúsculas): arte vivido, arte transformador, arte capacitador, arte constructivo y construido a partir de la necesidad de dar sentido a la experiencia de vida. Arte como herramienta de conocimiento personal y colectivo, arte que investiga y ofrece nuevas formas de hacer y de contar, compartir en definitiva. 
241) cuando sugiere que la educación tiene grandes cosas que aprender de las artes. Por ejemplo menciona:

Una lección que enseñan las artes es que puede haber más de una respuesta a una pregunta y más de una solución a un problema; la variabilidad de los resultados se acoge con agrado [...] Otra lección que la educación puede aprender de las artes es que la manera de formar algo tiene importancia [...] lo que se dice no se puede separar sin más de cómo se dice. La forma y el contenido se interpretan mutuamente [...] la interpenetración entre el contenido y la forma es una concepción fundamental que revelan las artes.

- La tesis/obra: Eisner abre un tema que, de algún modo, libera a la investigación en Bellas Artes del yugo de los cánones en investigación en otras áreas, en los que hay estructuras, metodologías y parámetros narrativos de cómo se debe escribir y/o presentar un trabajo de tesis doctoral para que entre a su valoración con un formato reconocible y cuyas formulas evaluadoras están predefinidas. Liberación que debería permitirnos seguir con la inercia que como creadores tenemos y desarrollamos en cada cosa que hacemos. Deberíamos sentir la confianza de buscar las estructuras de representación físicas más adecuadas para nuestro trabajo, y no constreñirlo en configuraciones predeterminadas si éstas pueden provocar que los trabajos se desvirtúen, en aras de complacer el orden establecido en un contexto en el que las pautas de investigación en humanidades (que es donde generalmente se nos engloba) nos queda bastante lejos. Pero no solo en su representación física, como "libro", si no también en su defensa ante el tribunal, en la que salirse de los parámetros que marcan una presentación-resumen de la tesis (en la que el doctorando se apoya para ir describiendo los aspectos más importantes de su trabajo), no suele dejar cabida a otras invenciones de defensa en otras áreas que no sean las artes, o al menos no están contempladas como tal. Como un miembro de mi tribunal de tesis dijo:

Cuando a nosotros nos llega una tesis como ésta hay que hacer un ejercicio un poco mayor que con las tesis clásicas [...], también me parece un trabajo muy interesante la manera de exponerlo [...] en esa representación en la que de algún modo yo entendía que también estaban los tres discursos (Marián López Fdz. Cao. 2010).

Lo que quiero decir, es que no sólo por tratarse de tesis que versan sobre procesos artísticos personales deben de buscar otras formas de representarse, si no que además podemos ofrecer nuevos ejemplos que estén en absoluta concordancia con la esencia de nuestro trabajo. Cualquier trabajo de investigación no debería sacrificar su propia identidad como tesis/obra para estar al servicio de lo establecido, que fue creado en un paradigma de investigación en el que el cuerpo, la opinión personal o las experiencias fruto de reflexiones y decisiones tomadas por el sujeto investigador no eran consideradas dentro del trabajo, lo que no quiere decir que no dieran lugar durante el proceso. Afortunadamente son varios los departamentos y directores/as de tesis que van permitiendo que en los trabajos que dirigen esté presente el cuerpo del investigador, como sujeto activo y vivo dentro de la investigación, creándose metodologías y estructuras nuevas de investigación, sobre todo en educación y arte, 

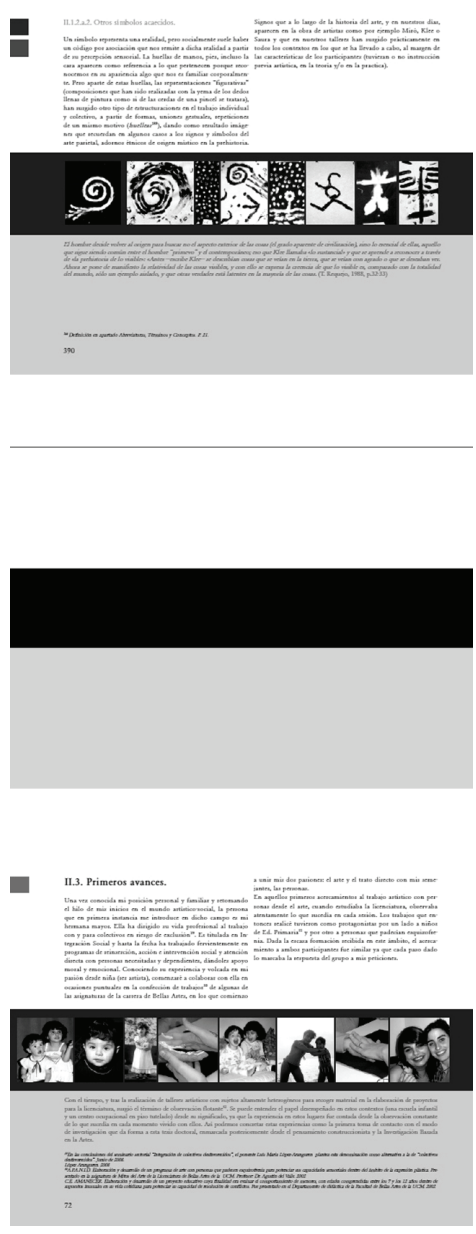

que pueden servir como modelo para otros/as, como experiencias (tesis) sobre los que iniciar/inspirar el nuestro ${ }^{6}$.

Posibles formas de narrar la experiencia.

- Modelo de redacción como experiencia significante: el triple relato:

En una tesis doctoral, en la que a priori la hipóte$\operatorname{sis}^{7}$ inicial no partía de la búsqueda de modelos que recrear, en aras de apoyar el discurso que se desprende de este texto, si concluimos con la aportación de dichos modelos sobre los que discurriese el contenido del trabajo de investigación. Una vez que dispuse y repasé todo el material para iniciar la redacción de la tesis concluí, junto con mi directora, que requería de un diseño específico narrativo que pudiera mostrar de manera simultánea la forma en la que había ido aconteciendo el proceso transformador identitario en el cuerpo/esencia de la figura del investigador, en la continua interrelación con el Otro:

La participación del Otro resulta fundamental en este encuentro como hallazgo que nos sorprende e inquieta, pero que siempre produce un nuevo conocimiento a integrar en nuestras identidades en permanente construcción". (J. Abad, A. Ruiz, 2009:6)

Así llegamos al triple relato: relato reflexivo, relato visual y relato documental:

Cada relato está ligado a una parcela conceptual de la investigadora:

El reflexivo, corresponde a lo que soy, de dónde vengo y hacia dónde me dirijo. Se cuenta el día a día, esperanzas, deseos, pretensiones y frustraciones, no hay adere-

${ }^{6}$ Cuando aprendemos a pintar, dibujar...la observación de cómo lo hacen otros nos sirve como modo de aprendizaje consciente; la lectura y visualización de estas tesis-obra también puede ayudar al mismo fin en el marco de la investigación (en todas las áreas, no solo en educación y arte).

${ }^{7}$ En el punto de partida, el trabajo situaba su foco en un marco de investigación artística que profundiza acerca del papel del arte como vehículo integrador y favorecedor de las interrelaciones sociales y la importancia de éstas para generar el auto-conocimiento y auto-cuestionamiento en la evolución y transformación identitaria del artista-investigador. Sobre ésto se interesaba por generar un trabajo de campo en el que a través de talleres de arte participativo, usando como recurso la huella corporal, pintura y tela, bajo la estética binaria blanco y negro, se sucederían los vínculos y conexiones con las diferentes áreas de conocimiento que, gracias a una documentación, reflexión y registro permanente, servirían como apoyo a los planteamientos y conclusiones alcanzados durante el proceso. 
zos, todo es narrado desde mi realidad. En él se exponen acontecimientos cotidianos, introspecciones y determinaciones fruto de vivencias personales y/o relacionales. Aparece aquello y aquellos que me rodean. De su redacción se desprende la sustancia de un tiempo en el que transcurre todo, de un tiempo no lineal, ya que se ve interrumpido por escenas que despliegan un recuerdo o una reflexión fruto de multitud de variables [...].

El visual expone, de un modo u otro, los iconos de los otros dos. No quiere decir ésto que las imágenes funcionen como apoyo gráfico de los textos, ni que tenga que hacerse de ellas una lectura analítica para su comprensión, si no que posee un discurso propio. Se trata de una selección de imágenes que presentan, en el hilo de lo que comunican el reflexivo y el documental, [...], los aspectos referidos en ambos relatos destacando uno u otro según el contenido. [...]. Es la ventana, se podría decir, al imaginario mental de esta investigación.

Dentro de este relato, en ocasiones aparece el concepto de no-imagen y all-image. Ambas combinaciones de términos poseen un sentido cada vez que se dan:

- no-imagen, quiere decir que no he encontrado ninguna imagen que pueda vincular con los planteamientos que se describen en los otros dos relatos [...].

- all-image, surge cuando el relato reflexivo y/o documental exponen planteamientos en cuya confección me han evocado tantas imágenes que no he sido capaz de decidirme por ninguna en concreto [...].

El documental [...] convive en él el espacio dedicado a lecturas, asistencia a cursos y seminarios, charlas con colegas, visionado de documentales, películas [...] en definitiva se refiere a todos los aspectos externos que asoman en la búsqueda para "cultivarse" (como siempre dicen mis padres), con todos los estímulos y referencias , formando una especie de red disforme a modo de sinergia que ayuda a comprender el tiempo mencionado como un tiempo real y verdadero, presente en cada libro, escena, conferencia o entrevista (de Miguel Álvarez, Laura. 2010: 37-38).

Este diseño estructural del discurso no muestra otra cosa que tres formas paralelas de dar a conocer la vivencia/experiencia mantenida durante los años de realización de la investigación que narran. El relato reflexivo es de donde parten los otros dos (visual y documental), es la médula sobre la que se yerguen imágenes y referencias que dan la posibilidad de relacionar sus sentidos o simplemente de presentar discursos que se pueden resignificar. 

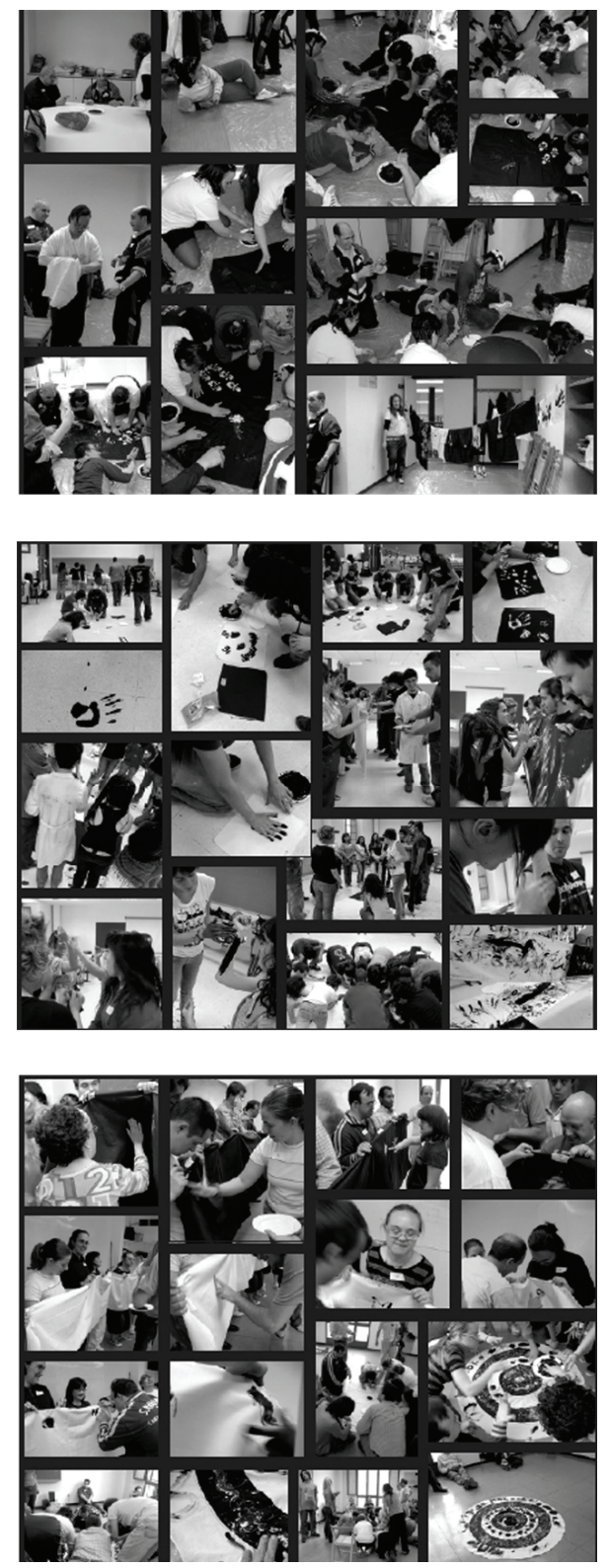

En su momento no hallamos ningún modelo o manual que nos ayudara a dar formato a la presentación de todo lo que queríamos contar, pero fuimos conscientes de que la formación continua en el campo de las artes, las lecturas, asistencia a exposiciones, y sobre todo las conversaciones/entrevistas con colegas del campo, contribuyeron a la confección del diseño final.

Convivencia con otras estructuras de narración. Dentro del relato visual ${ }^{8}$, las imágenes fluyen unidas a la palabra, como construcción de una identidad en continua transformación y modulación propia. Pero esta estructura, convive con otras:

- Narrativas visuales: Comprenden el mapeado de imágenes, que representan momentos congelados en la linealidad temporal durante la que acontecen, para mostrar explícitamente las diferentes acciones llevadas a cabo y referenciadas a lo largo de todo el Trabajo de Campo (T.C) del trabajo de investigación.

- Imagen-texto y Texto-imagen: Con la unión de los términos imagen-texto podemos entender el planteamiento de que las imágenes "hablan por sí mismas", pero en ocasiones éstas presentan un sentido que no es captado por todos a quienes se le ofrece, pues hay diversas variables que condicionan la lectura que hagamos de ellas. Pero la combinación de texto-imagen sugiere otra cosa. Para experimentar en sí este planteamiento, en lugar de definirlo, propongo la lectura concentrada de este texto: La gata se frotaba repetidamente contra la puerta de la habitación del abuelo, mi

\footnotetext{
${ }^{8}$ Me gustaría destacar la sugerencia que en la defensa de la tesis me hizo el Dr. Ricardo Marín, que apuntaba la necesidad de haber realizado un guión del origen de todas las imágenes que no habían sido realizadas por mí y que aparecían en el relato visual, provenientes de de libros, web, etc. Para así darles el mismo tratamiento que a las referencias escritas, que sí aparecían con su origen localizado.
} 
cuerpo se resquebrajó en un frío temblor. Apreté los dientes y me quede petrificado delante del cerrado dormitorio. Agarré el helado pomo, la gata seguía maullando lastimeramente, con una incómoda cadencia. Mis dientes a punto estaban de saltar, de estallar unos con otros. Abrí la puerta lentamente y todo lo demás dejó de existir durante unos instantes... No. El cuerpo de Teo, de mi abuelo..., yacía boca arriba en la cama, bien tapado y con ambos brazos por fuera de las sábanas, su cara estaba pálida e inexpresiva, su rostro había desaparecido. [...] (A. Vico, Mariano. 2011: 112)

La visualización que fluye fruto de la lectura de esta narración, provoca que la imagen mental cobre la misma importancia, o más, que si fuese imagen real que poder visualizar.

- Formato de diario de campo: Se trata de exponer íntegramente las anotaciones tomadas en el transcurso de la práctica, en convivencia con las narrativas visuales de cada taller. De este modo se hace visible, no solo el proceso, sino también la voluntad del investigador/a. De forma clara se percibe su motivación personal, que le hace tomar decisiones en función de los diferentes estados anímicos y personales por los que atraviesa durante el proceso. Lo que nos lleva a hacer de la investigación una inquietante y tarea más del día a día, incluyendo parte de las cotidianidades en el relato del T.C. de la propia tesis doctoral.

- Exposición de resultados (restos) como experiencia estética durante la narración: Es la forma sobre el soporte de papel, en la que podemos presentar los resultados de los talleres del T.C. Se propone la muestra íntegra de todos los resultados fruto de la investigación, ya que consideramos que es la manera de poder brindar un homenaje a todas las personas que han formado parte de una investigación compartida, construida por todos pero presentada por uno. Es la forma de seguir agradeciendo su tiempo, esfuerzo, implicación y dedicación desinteresada. Su disposición puede considerarse como experiencia estética que disfrutar dentro de la propia narración. El disfraz de objetividad. 
4. ANTECEDENTES

5. PERSPECTIVAS DE INVESTIGACIÓN

6. MARCO TEÓRICO

\section{METODOLOGÍA DE INVESTIGACIÓN}

\section{CONTEXTOS DE ACTUACIÓN}

9. DESARROLLO DEL TC

10. CONCLUSIONES

11. BIBLIOGRAFÍA

12. ANEXOS

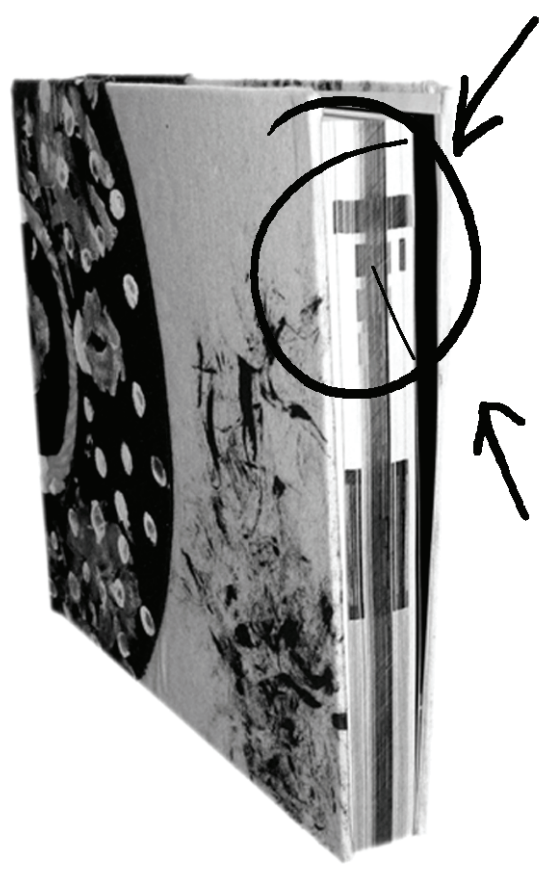

Una vez escuché: "somos sujetos, por lo tanto somos subjetivos"'. Para comenzar este apartado, es importante que reflexionemos en torno a la cuestión ¿Qué es investigar? Posiblemente podamos dar muchas respuestas, y de hecho eso denotaría que estamos en el camino adecuado, pues tratar de dar una única respuesta a ésta ( $\mathrm{u}$ otras cuestiones) va en detrimento de lo que de por sí puede sugerirnos tal acción: investigar, limitando así la capacidad del propio investigador de trasladar el resultado de sus experiencias a otros contextos a fin de obtener nuevas interpretaciones de las mismas en la continua generación y regeneración del conocimiento. Pues bien, se trata de un verbo que implica una acción, que es desarrollada por un sujeto vivo, rodeado de infinidad de variables circunstanciales sujetas a su contexto, espacio y tiempo. Tratar de eludir éstas, apartarlas, desecharlas, no conlleva otra cosa que dejar aspectos propios del proceso indagador fuera del mismo. Serán partes del proceso que no conoceremos si no son mostradas por el agente investigador, individual o en equipo. Pues bien, éste es uno de los problemas del disfraz de la objetividad, pero cabe destacar otro que me resulta más controvertido aún. En este paradigma de relación permanente entre Investigación/Arte/Vida algunos siguen empeñados en que utilicemos la tercera persona, el plural mayestático... porque se considera que es la manera de hacer ver que lo que estas escribiendo es una aportación a la comunidad científica, que las reflexiones y planteamientos narrados a lo largo de tu discurso son fruto del encuentro y debate con referencias dentro del área de investigación... pero, ¿por qué no decir esas referencias, narrar esos encuentros explícitamente?. De por sí sabemos que lo que escribimos queda para todos, lo compartimos y tratamos que

${ }^{9}$ Fernando Hernández Hdz., 2007. 
los escritos de otros fluyan en el mismo sentido. No se puede narrar la experiencia propia desde fuera, o al menos intentar que así lo parezca. Yo utilizo el plural cuando algunos somos y estamos, y la primera persona del singular, cuando yo soy y estoy ${ }^{10}$.

Mecanismos de articulación alcanzados hasta ahora.

Se trata de pequeñas aportaciones que pueden ir contribuyendo a crear un listado de mecanismo que nos ayuden a la hora de situar cada una de las partes de nuestro trabajo dentro del paradigma de Investigación/Arte/Vida. Partes que no vemos la forma de su inclusión a través de otros modos de representación de tesis en cualquier área. A través de la experiencia de mi propia redacción de tesis doctoral llegamos a:

- Actividades Conductoras: Denominaremos de este modo a aquellas actividades, talleres, comunicaciones o actos, en los que vayamos participando en el transcurso de nuestra investigación, que formen parte de ella pero no se incluyan en el flujo posterior y lineal, cronológicamente hablando, de lo que más adelante expondremos bajo las siglas T.C (Trabajo de Campo). Conductoras porqué nos van conduciendo, dejando parte de su diseño y desarrollo, en los talleres posteriores proyectados y desarrollador para el T.C.

- Correspondencia: Según como planteemos nuestra tesis, ésta va a ir discurriendo por los diferentes epígrafes que establezcamos en el índice de la misma. Esa estructura, también condicionará el tono del discurso que hagamos, por lo que con Correspondencia tratamos de dar una solución para aquellas investigaciones cuyos epígrafes de tesis no encajen con los considerados como convencionales de una tesis doctoral, según diversos manuales:

1. INTRODUCCIÓN.

2. EXTRACTO DEL CONTENIDO DE CADA BLOQUE.

3. MOTIVACIONES PERSONALES.

4. ANTECEDENTES.

5. PERSPECTIVAS DE INVESTIGACIÓN.

6. MARCO TEÓRICO.

7. METODOLOGÍA DE INVESTIGACIÓN.

8. CONTEXTOS DE ACTUACIÓN.

- Hipótesis.

- Objetivos.

- Metodología.

9. DESARROLLO DEL T.C.

10. CONCLUSIONES.

11. BIBLIOGRAFÍA.

12. ANEXOS.

\footnotetext{
${ }^{10}$ Se refiere al hecho de aparecer presentes, en cuerpo, mente y espíritu (sensibilidad) dentro del discurso, sin adornos ni artificios narrativos que traten de invisibilizar-me (-nos). Aunque para llegar a esto he sorteado y superado mis propios prejuicios, y también he aprendido mucho de aquellos que llevan tiempo defendiendo este planteamiento.
} 
¿Cómo establecemos la correspondencia? Por čolores. Las secciones anteriores, componen el guión de una tesis que dispone el contenido por apartados a los que se puede acudir para conocer esa parte de la información. Por lo que en un trabajo de investigación en el que no hayamos visto oportuno distribuir el contenido bajo estos epígrafes, y para facilitar al lector de nuestro trabajo la localización de estos encabezamientos eminentes y no existentes como tal, establecemos una correspondencia por colores que puede consultarse si se presta atención a la lectura de la cara interior del lomo de la tesis (a las pequeñas marcas de color en su parte superior), donde al dirigirnos, por ejemplo, al color rojo, conoceremos las conclusiones del trabajo de investigación, sin tener que leer el tomo completo.

- Neologismos:

Un neologismo es una palabra nueva que aparece en una lengua, ya sea procedente de otra lengua o de nueva creación. Con ese impulso creador con el que podemos enfrentarnos a la redacción de nuestro trabajo, puede surgir la necesidad de nombrar de forma diferente algunas de las partes de dicho trabajo para que su acepción tenga más relación con la naturaleza de la tesis-obra en sí. Algunos ejemplos que podemos ofrecer son:

Poso: Término que posee un sentido de quietud, espera, a la vez que evoca la sensación de silencio, introspección y calma. Por otro lado poso, como imagen simbólica, es lo que nos ha quedado al destacar algunos aspectos determinados del trabajo en el apartado de poso=conclusiones, con el fin de "atar" algunos de los puntos que se exponen a lo largo de la redacción a modo de conclusión pero que no han sido concretados específicamente.

Restos (término acuñado por el filósofo Jaques Derrida, que resignificamos en nuestra investigación): De este modo hemos designado al conjunto de todos los resultados fruto de los talleres realizados en el seno del T.C. Éstos representan la necesidad de apertura hacia otras direcciones de las que son parte, una parte finita de lo que espera acontecer, ellos (los restos) han quedado como la evidencia de un cambio hacia una nueva transformación en la continua búsqueda de ser.

Entre otros.

- Intersticios metodológicos: En este apartado me gustaría reflexionar acerca de la posibilidad que hemos probado de la no limitación a los terrenos inherentes a una investigación desde la perspectiva más convencional (la metodología, hipótesis, objetivos...), a través de cuyos huecos hemos intervenido con métodos quizás no tan convencionales, pero igual de efectivos para el avance de la investigación como: la toma de decisiones fruto de un estado de ánimo concreto, la intuición sobre la marcha dando giros en la acción o las tomas de decisión llevadas a cabo por corazonadas, emoción y/o desánimo. Estos métodos podrían enmarcarse en los intersticios de metodologías utilizadas en la investigación en ciencias humanas y sociales. Por lo que, desde una perspectiva epistemológica, su definición sería: Huecos, vacíos, recovecos...por los que se introducen aspectos poco reconocidos en las definiciones de las diversas metodologías "válidas" para llevar a cabo un proyecto de indagación pedagógica, social, artística, como por ejemplo lo son los estados de ánimo, la intuición, T.C. 


\section{POSO}

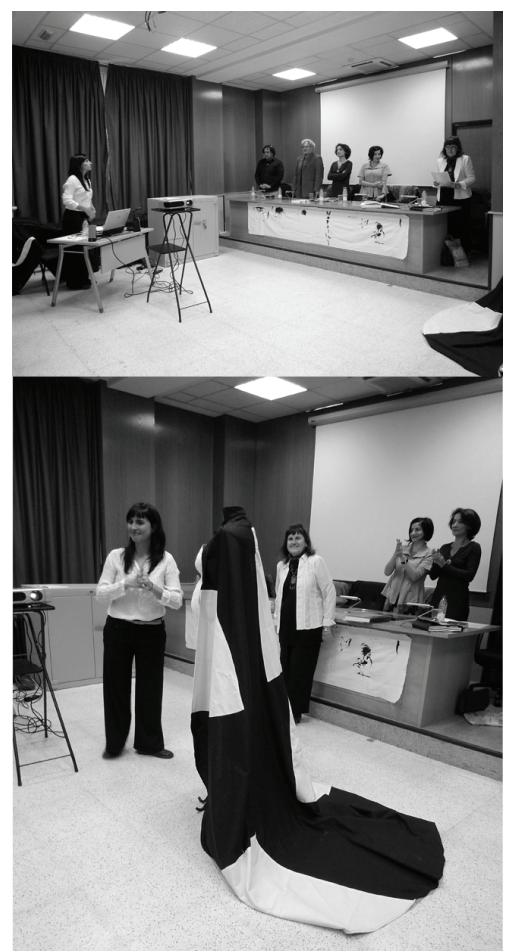

La defendí, y la vida siguió. El final no llega con la tesis, si no que comienzas a vislumbrar el largo camino que se encuentra tras la puerta que acabas de abrir con la defensa de la misma (como me decía mi directora). Es cierto que el mundo de la investigación es apasionante, sin más, pero también requiere mucho tiempo, dedicación, reflexión, lectura, encuentros, etc. Situaciones que, en ocasiones, pueden resultar atropelladas por no encontrar el momento de compaginarlas con la vida personal, privada. Tal vez, éste fue uno de los motivos que me condujo de forma inconsciente (a la vez que necesaria) a hacer del proceso de indagación (durante los años de tesis), el núcleo sobre el que desenmarañar los hilos de la experiencia de vida pasada y presente. De lo cual me alegro, porque el tejido creado me ha permitido fluir por un terreno de investigación en el campo de las Bellas Artes que me resulta no solo apasionante, también vital.

Ahora, en mis días, en mis clases, en mis encuentros, desencuentros, pasiones, relaciones, pensamientos, sueños, creaciones, llantos... sé que podría encontrarse el germen de mi próximo proyecto de investigación, individual o compartido. 


\section{REFERENCIAS BIBLIOGRÁFICAS}

A. VICO, M. (2011) Perdiendo el Sur. Madrid. Edición propia.

ABAD MOLINA, J.; RUIZ DE VELASCO, A. (2009). Ecología Humana: Espacios, Relaciones y Sentidos. Madrid. Ed. Centro Universitario la Salle.

AGUILAR, V. (2011) El Abrazo del Oso. Barcelona. Ed. Luciérnaga.

AA.VV. (2006) El libro Blanco de la investigación en Humanidades. Fundación Española para la Ciencia y la Tecnología (FECYT).

DE MIGUEL ÁLVAREZ, L. (2010) Tesis Doctoral: La huella, la tela, el blanco y el negro en la manifestación de ser. Modelo de confección autoidentitaria del artista-investigador-educador. Directora: Dra. Ana Mampaso Martínez. Dto. De Didáctica de la Expresión Plástica. Facultad de Bellas Artes. Universidad Complutense de Madrid. Publicada.

EISNER, E. W. (2004). El arte y la creación de la mente. Ed. Barcelona. Paidós Arte y Educación.

STEINER, G. (1991) Presencias Reales. Barcelona. Ed.

ZUBIZARRETA, M. L.. (1998) Prosody, focus and word order. Cambridge, Mass.: MIT Press.

\section{OTRAS FUENTES}

HERNÁNDEZ HDEZ. F. (07 de octubre 2011) Seminario: La Investigación Basada en las Artes: el Giro Performativo de las Ciencias Sociales. Madrid. Universidad Antonio de Nebrija.

LÓPEZ FERNÁNDEZ-CAO, M. (15 de octubre de 2010) Acto de defensa de la Tesis Doctoral: La huella, la tela, el blanco y el negro en la manifestación de ser. Modelo de confección autoidentitaria del artista-investigador-educador. Facultad de Bellas Artes. Universidad Complutense de Madrid.

MEC. (2007) Programa Aulas de la Naturaleza. BOE no 27.

\section{ORIGEN DE REFERENCIAS VISUALES}

Imagen 01: Páginas de la tesis doctoral de Dra. Laura de Miguel Álvarez (2010).

Imagen 02: Páginas de la tesis doctoral de Dra. Laura de Miguel Álvarez (2010).

Imagen 03: Tesis/obra de la Dra. Laura de Miguel Álvarez (2010).

Imagen 04: Acto de defensa de la tesis doctoral de Dra. Laura de Miguel Álvarez (15 octubre de 2010).

Autora de dibujos-texto: Laura de Miguel Álvarez. 